\section{SIGNIFICADO DADO AL SECUESTRO DE MIEMBROS DE LA FUERZA PÚBLICA EN EL CONTEXTO DEL CONFLICTO ARMADO COLOMBIANO*}

\author{
MEANING GIVEN TO THE KIDNAPPING \\ OF MEMBERS OF THE SECURITY FORCES \\ IN THE CONTEXT OF THE COLOMBIAN \\ ARMED CONFLICT
}

SIGNIFICADO DADO AO SEQUESTRO DE MEMBROS DA FORCA PÚBLICA NO CONTEXTO DO CONFLITO ARMADO COLOMBIANO
Orlando Díaz Marroquín ${ }^{a}$ juriordima@hotmail.com Fecha de recepción: 17 de agosto de 2016 Fecha de revisión: 12 de septiembre de 2016 Fecha de aceptación: 24 de septiembre de 2016

\title{
RESUMEN
}

El presente artículo buscó responder qué actores y discursos participan en la construcción de significado del secuestro de miembros de la Fuerza Pública (Ejército y Policía) en el contexto del conflicto armado colombiano. Para tal fin la investigación se apoyó en la recopilación de los registros históricos de esta modalidad delictiva que visibilizan el hecho en sí, pero en muchos casos mediatizan la opinión pública y la posición estatal hacia minimizar el rol y responsabilidad de los Grupos Armados Ilegales (GAI) cuando violan los Derechos Humanos (DDHH) y transgreden el Derecho Internacional Humanitario (DIH); lo anterior al extraer a los miembros de la Fuerza Pública del universo de victimas del secuestro. Por lo tanto, el significado de tales secuestros que subyace en dichos discursos tiende a ofrecer una visión sesgada de la realidad al resaltar solo la dramática situación de la sociedad civil, pero no de quienes están a cargo de la defensa de los valores democráticos del Estado Social de Derecho consagrado en la Carta Política de 1991, del ordenamiento jurídico en la materia y del bloque de constitucionalidad en DIH.

* Artículo producto de investigación presentado en el marco de la formación en Magister en Derechos Humanos y Dica.

a. Abogado de la Universidad Autónoma de Colombia, Magister en Derechos Humanos y Dica, Escuela Superior de Guerra, especialista en derecho laboral y seguridad social de la universidad Republicana y en derecho tributario y aduanero de la universidad católica de Colombia.

MISIÓN JURÍDICA

Revista de Derecho y Ciencias Sociales Bogotá, D.C. (Colombia)

Colaboradores Externos Nacionales

Núm. 12 Año 2017

Enero - Junio pp. 259 - 278

ISSN 1794-600X 


\section{PALABRAS CLAVES}

Discursos sobre el secuestro, miembros de la fuerza pública, Grupos Armados Ilegales (GAI), conflicto armado, DD.HH, DIH.

\section{ABSTRACT}

This article originated in the following question: What actors and whose speeches are involved in the construction of meaning of the abduction of members of the Security Forces (Army and Police) in the context of the internal armed conflict in Colombia? This question is based on the gathering of historical records of this criminal modality making visible the fact itself, but in many cases the influence on public opinion and the State position to minimize the role and responsibility of the illegal armed groups (GAI) when they violate Human Rights (HR) and transgress the International Humanitarian Law (IHL), to remove the members of the Public Forces away from the universe of kidnapping victims. Therefore, the meaning of such abductions that underlies these speeches tend to offer a skewed view of reality to highlight only the dramatic situation of civil society but not of those who are in charge of the defense of the democratic values of the Social State of Law enshrined in the Constitution of 1991, in the set of laws in the matter and in the block of constitutionality on International Humanitarian Law.

\section{KEY WORDS}

Speeches on abduction, members of the public forces, Illegal Armed Groups (GAI), armed conflict, Human Rights, International Humanitarian Law.

\section{RESUMO}

Este artigo procurou responder quais atores e discursos estão envolvidos na construção do significado do sequestro de membros da força pública (exército e polícia) no contexto do conflito armado colombiano. Para este fim, a pesquisa foi apoiada na coleta de registros históricos deste tipo de crime que tornam visível o ato em si, mas em muitos casos mediatizam a opinião pública e a posição do Estado para minimizar o papel e a responsabilidade dos grupos armados ilegais (GAI) quando violam os Direitos Humanos (RH) e violam o direito Internacional humanitário (DIH); isto para remover membros das forças do universo das vítimas de sequestro de segurança. Portanto, o significado de tais sequestros subjacentes a esses discursos tende a proporcionar uma visão distorcida da realidade, destacando apenas a situação dramática da sociedade civil, mas não dos encarregados da defesa dos valores democráticos do Estado Social de Direito consagrado na Constituição de 1991 e do bloco de constitucionalidade em DIH.

\section{PALAVRAS-CHAVE}

Discursos sobre o sequestro, membros da força pública, grupos armados ilegais (GAI), conflito armado, DH, DIH.

\section{INTRODUCCIÓN}

El presente artículo tiene como propósito caracterizar los actores y analizar los significados históricos, jurídicos y sociales de sus discursos, referidos al secuestro de miembros de la Fuerza Pública (Ejército y Policía), en el marco del conflicto armado interno colombiano por parte de los GAI (específicamente las autodenominadas Fuerza Armadas Revolucionarias de Colombia, en lo sucesivo FARC-EP y el Ejército de Liberación Nacional en lo sucesivo ELN) y desde la violación de los DDHH y la trasgresión del DIH.

En el Derecho internacional el secuestro se ha entendido como una de las formas violatorias de los Derechos Humanos, según lo señala la Organización de las Naciones Unidas (ONU) en los artículos 1, 3, 5 y 9 de la Resolución 217 de 1948; en la Resolución 2003-28 y en la Resolución 59-154 de febrero 3 de 2005, entre otras, así como una forma de transgresión del Derecho Internacional Humanitario (DIH), a partir de 2002, de acuerdo con las Resoluciones del Consejo Económico y Social, del cual hace parte la Comisión de Derechos Humanos de la ONU, aprobadas por la Asamblea General y suscritas por los países parte y el artículo 3 común a los cuatro Convenios de Ginebra; Artículo 75.2c del Protocolo Adicional I y Artículo 4.2c del Protocolo Adicional II. En estos Convenios y Resoluciones posteriores, el secuestro se reconoce como:

Un delito que no solo afecta a la víctima, sino también a su familia y a toda la sociedad, ya que son expuestas en general a una presión sicológica de miedo y angustia, a fin de lograr su objetivo, cual es la obtención de 
un rescate. Por ello, este acto punible es una violación de uno de los derechos humanos más elementales que todos poseemos, cual es la libertad, circunstancia que hace al delito de secuestro, como uno de los más deleznables actos que una persona pueda cometer (Artículo 75.2c del Protocolo Adicional I y Artículo 4.2c del Protocolo Adicional II.).

De igual manera, el secuestro es entendido como:

Detener ilícitamente a una persona o personas en contra de su voluntad con la finalidad de exigir por su liberación un provecho ilícito o cualquier utilidad de tipo económico u otro beneficio de orden material, o a fin de obligar a alguien a que haga o deje de hacer algo (Resolución 2002/16 del Consejo Económico y Social).

Es importante tener en cuenta que, aunque el texto de los protocolos antes mencionados no hacen referencia explícita de los miembros de la Fuerza Pública en condición de secuestrados, basta tomar en consideración que usualmente aparecen este tipo de espacios en los marcos normativos internacionales que las legislaciones nacionales complementan en su bloque de constitucionalidad y que la sola condición de seres humanos es suficiente para ameritar y extender la protección de su condición existencial. Esto lo ha reconocido la Corte Constitucional (CC) en la Sentencia C-456 de 1997, cuando declaró inexequible el artículo 127 del Decreto 100 de 1980 (Código Penal colombiano), que pretendía concederles total impunidad a los guerrilleros que cometieran crímenes de todo tipo, en nombre de supuestos ideales políticos:

Los miembros de las Fuerza Pública, no sobra recordarlo, no agotan como servidores públicos su dimensión existencial. Ante todo, se trata de personas y como tales, salvo los derechos que la Constitución expresamente no les otorga, gozan de los restantes. El aparato estatal requiere del esfuerzo y concurso de los militares y policías, con el objeto de cumplir misiones tan esenciales como las referidas a la defensa del territorio, la independencia nacional, la democracia y los derechos fundamentales. No obstante, el miembro de la Fuerza Pública no termina absorbido por el aparato estatal, como lo pretende una visión deshumanizadora $y$ contraria a la dignidad de la persona humana.
En este orden de ideas, atentar contra la vida de un miembro de la Fuerza Pública, no se concreta en la simple lesión de un valor institucional. Los militares y policías no son entelequias $\mathrm{y}$, por tanto, el más elemental entendimiento de la dignidad humana, no puede negarles el carácter de sujetos pasivos autónomos de los agravios que desconozcan su personalidad y su vida.

(...) Los miembros de la Fuerza Pública están prestando un servicio público y cumpliendo funciones constitucionales, en tanto que los rebeldes o sediciosos forman parte de grupos que se encuentran fuera de la ley y hoy por hoy se dedican al narcotráfico, al terrorismo, al secuestro, a las torturas y atentan permanentemente contra los derechos fundamentales de los colombianos y contra el sistema democrático que rige el comportamiento político de la República (CC., 1997).

Adicionalmente, el motivo de un secuestro, así como el resultado buscado por los GAI, varía significativamente, por eso la ONU (Resolución 2002/16 del Consejo Económico y Social - Manual de lucha contra el secuestro) ha visto la necesidad de clasificar esta modalidad delictiva en nueve casos, siendo el segundo, el que hace alusión a las circunstancias en que ocurre el secuestro de miembros de la Fuerza Pública, al señalar que:

"El secuestro con fines políticos o ideológicos, cuyo objetivo puede ser destacar una reivindicación particular, -tiene como finalidad- crear una atmósfera de inseguridad (o reforzarla), obtener publicidad o influir en decisiones de gobiernos $u$ otras entidades (ONU, 2005, p. 3)

Tales pronunciamientos de la ONU resultan de gran importancia para lo que ha sucedido por más de cincuenta años en Colombia, donde miles de personas de todas las condiciones sociales y económicas, junto con miembros de la Fuerza Pública, han resultado víctimas del secuestro, engrosando las estadísticas nacionales e internacionales y concitando los esfuerzos de organizaciones oficiales y no gubernamentales, así como la de investigadores independientes, para tratar de llegar a un consenso acerca de las cifras reales de este delito, lo cual se ha dificultado, así lo señala el Centro Nacional de Memoria Histórica (CNMH). 
Por la falta de información antes del año 1991; el subregistro de secuestrados ocasionado por la ausencia de denuncias; la fragmentación de los datos en diversas entidades, los múltiples cambios en la definición legal y jurisprudencial del delito, e incluso, las decisiones de política pública que afectan las estadísticas oficiales" (CNMH, 2010, p. 6).

Estas falencias en el registro de personas secuestradas no solo se refieren a población civil afectada sino también a miembros de la Fuerza Pública, observándose el énfasis puesto por las diferentes organizaciones públicas y privadas, encargadas de su recopilación, en la manera de subrayar sus impactos en la sociedad, los cuales en un Estado social y democrático de derecho como es Colombia, revelan una significativa distancia entre las realidades sociales, políticas, económicas y culturales nacionales y el deber ser del ejercicio pleno de los DDHH fundamentales, así como del no acatamiento del DIH por los GAI como directos responsables de secuestrar militares y policías.

$\mathrm{Al}$ respecto de lo anterior, es evidente que la persistencia del conflicto interno y la falta de resolución de las problemáticas socioeconómicas y políticas que le dieron origen, han limitado las posibilidades para el goce pleno de estos derechos y por supuesto, muestra el grado de incapacidad del Estado colombiano para garantizarlos, es por ello que suelen presentarse como fragmentados y constituirse a su vez en la fuente de violación de los DDHH, de transgresión del DIH y de perturbación del orden institucional.

Como se ha podido apreciar, la retención de personas en Colombia, en este caso, miembros de la Fuerza Pública, en su calidad de representantes legítimos del Estado, por cualquier GAI, es una acción que va en contra del ordenamiento jurídico nacional e internacional puesto que constituye un acto mediante el cual estos grupos tratan de demostrar, por una parte, fuerza beligerante en busca de legitimación ante la comunidad internacional, al denominar a los retenidos "prisioneros de guerra" y, por otra, reclaman un poder político y un marco de acción judicial.

Los criterios anteriores permiten plantear como hipótesis deductiva que los discursos estatal y civil, en el ámbito del conflicto armado colombiano, tienden a invisibilizar, en relación con el secuestro de miembros de la Fuerza Pública, la vulneración en ellos de sus DDHH y la infracción del DIH realizado por parte de los GAI, quienes tratan de presentar este acto delincuencial no solo como otra forma de lucha, sino como una demostración de su capacidad para deslegitimar el poder del Estado y un medio para disminuir la moral de quienes los combaten en su nombre.

\section{MÉTODO}

A lo largo de la etapa de recolección y composición del corpus informativo que permitió adelantar el proceso de análisis del presente artículo, se empezaron a generar textos sobre los textos consultados, poniéndose en evidencia que el lenguaje de los discursos originales no era totalmente transparente, porque la connotación iba con la denotación que el lenguaje utilizado mostraba, pero al mismo tiempo ocultaba e incluso llegaba a distorsionar lo que pretendía reflejar el pensamiento de sus autores; aunque en la mayoría de los casos eran menos explícitos y sutiles al mismo tiempo.

Es aquí donde al observar cómo los discursos se convierten en escenarios donde se reproducen las representaciones individuales y colectivas, así como los prejuicios y estereotipos alrededor de una temática en particular, conducen a aceptar el ejercicio discursivo desde una perspectiva de "vínculos y relaciones sociales" (Laclau y Mouffe, 2004, p. 72).

Con el fin de llegar a obtener información confiable acerca del secuestro en Colombia y los discursos que circulan acerca del mismo, identificando a víctimas y victimarios, desde el momento en que esta modalidad criminal se convirtió en uno de los principales temores de la sociedad colombiana, fue necesario recurrir a diversas fuentes, cuyas bases de datos no siempre eran coincidentes en las cifras ni en los periodos de ocurrencia de los distintos casos, lo que arrojaba dudas acerca de su grado de credibilidad. Las discrepancias eran mayores cuando se indagaba acerca de los miembros de la Fuerza Pública víctimas de este mismo delito.

En suma se encontró información fragmentada, incluso en la cual se destacaban las mutuas acusaciones entre entidades por sobreestimación o subestimación de los datos, por ejemplo Fondelibertad (2013) reconoce 
24.026 casos de secuestro entre 1996 y 2009, el Instituto Nacional de Medicina Legal y Ciencias Forenses, afirma que entre 1985 y 2014 tiene registros de más de 77.000 cuerpos fichados como NN de los cuales no sabe cuántos han sido víctimas de secuestro; por su parte la prensa escrita entre 1980 y 2010 estima solo 15.251 secuestrados, mientras que César Caballero de la empresa de consultoría Cifras y Conceptos (2013), en su recopilación y depuración de datos entre 1970 y 2010, habla de 39.058, cifra retomada por el CNMH (2014) para sus estudios.

Lo anterior indica gran diversidad de modos de estimar los elementos constituyentes del fenómeno del secuestro, para elaborar una estadística única, puesto que a lo largo del tiempo también se dieron cambios significativos en las definiciones legales, lo que repercutió en los registros oficiales y de las $\mathrm{ONG}$ involucradas, entre ellas Amnistía Internacional (AI) y Human Rights Watch (HRW). Debido a lo anterior se observa que, en la citación de secuestrados, los miembros de la Fuerza Pública como tales, ni tampoco aparecen diferenciados del resto de ciudadanos, simplemente pareciera, sobre todo para algunas ONG internacionales, que no son víctimas sino simples combatientes retenidos en acciones de guerra, lo cual también altera las cifras de los registros históricos del periodo entre 1980 y 2013 (HRW, 2013, p. 1). En oposición a tales supuestos, el Estado colombiano finalmente reconoció a los miembros de la Fuerza Pública el estatus de secuestrado, lo cual no solo permitió conocer cifras oficiales de los afectados, sino garantizarles el derecho a sus ascensos y sueldos durante el tiempo de cautiverio (Ley 1279 de enero 5 del 2009).

En cuanto a las fases metodológicas del presente artículo, en primer lugar se dio inicio a la búsqueda de información tanto del número de casos de secuestro, de preferencia que hicieran mención a miembros de la Fuerza Pública, como de los discursos provenientes de fuentes jurídicas, históricas y sociales, al igual que de las víctimas y victimarios. En segundo lugar, se hizo un esfuerzo epistemológico por establecer las definiciones que fueran pertinentes con el tema tratado. En tercer lugar, se procedió a la consolidación de la información procedente de las distintas fuentes consultadas. En cuarto lugar, se dio inicio a la búsqueda de los significados contenidos en los discursos, aplicando el Análisis del Discurso (AD), el cual se inscribe en el paradigma cualitativo interpretativo, y propone una lectura inductiva para la construcción de categorías emergentes que surgen de las fuentes consultadas como: leyes, sentencias, informes internacionales, discursos políticos, de los medios masivos de comunicación e investigaciones teórico-empíricas sobre el fenómeno del secuestro en Colombia.

\section{EL FENÓMENO DEL SECUESTRO DE MILITARES, POLICÍAS: PERPETRADORES Y VÍCTIMAS}

A continuación se hace referencia al secuestro, entendido en el plano discursivo como un fenómeno en permanente cambio, con la capacidad para construir significados y fomentar simbolizaciones con relación a la condición de víctimas y victimarios. En sí, el secuestro, muestra una faceta hermenéutica porque a través de ella la sociedad colombiana y la comunidad internacional recepcionan e interpretan sus repercusiones. $\mathrm{Al}$ aprender a convivir con la noticia de la pesca milagrosa, la quema de vehículos, los atentados en zonas urbanas y la muerte de personas en cautiverio, la retención de miembros de la Fuerza Pública tiende a subsumirse en el diario vivir.

Es por ello que el discurso de los GAI prescinde de menciones concretas a los efectos de sus acciones en la sociedad civil, a la que en todo momento intentan polarizar entre quienes están a favor y quienes en contra de ellos. Este enfoque estratégico del secuestro no surgió en sus primeras apariciones sino que fue cobrando forma, por una parte, mediante el empleo de una cuidadosa argumentación que les permitió generar construcciones que poco a poco se han ido perfeccionando, tras la búsqueda de una máscara de legitimidad para su accionar delincuencial; por otra, a partir de algunos casos considerados inicialmente como hechos aislados pero que redituaron considerables ingresos a sus perpetradores; esta modalidad delictiva pasó a convertirse en un modus operandi, exigiendo reajustes jurídicos y conceptuales para enfrentarlo.

Un ejemplo de lo anterior que causó el repudio generalizado de la sociedad de la época, con gran despliegue en la prensa nacional, fue el secuestro en 1933 con fines extorsivos por la delincuencia común de la niña Elsa Eder, por ser hija de Harold Eder un acaudalado empresario azucarero y político del Valle del Cauca, pero en ese momento el delito fue considerado un rapto: 
"tal hecho condujo a que en 1936, se modificara el Código Penal tipificando como secuestro este acto delincuencial" (Rubio, 2008, p. 8-9).

Según Rubio (2008), 32 años después, durante la presidencia de Guillermo León Valencia (19621966), el mismo empresario padre de la niña secuestrada en 1933 y exministro de Estado "fue secuestrado por motivos extorsivos por Pedro Antonio Marín, jefe de un GAI que posteriormente sería conocido como las FARC, muriendo a los pocos días víctima de las heridas causadas al momento del plagio" (p. 9). Esto llevó al gobierno nacional a declarar tal acto, como "un atentado a la seguridad nacional" (p. 9). Es preciso recordar que en diciembre de 1963, dos años antes del secuestro del exministro Harold Eder, el mismo Marín, conocido ya bajo los alias de Manuel Marulanda Vélez o Tirofijo, realizó varios actos contra militares, policías y civiles.

Este tipo de acciones de las FARC le dieron pleno sentido al concepto de Seguridad Nacional, bandera del gobierno de Turbay Ayala (1978-1982). Indagando en su etimología "Seguridad", proviene del latín securitas, sin temor o despreocupado; y la palabra "Nacional", ha sido utilizada desde la antigüedad, puesto que las Ciudades-Estado y luego los Estados nacionales "han valorado en gran medida el sentimiento de protección que proporciona un Estado frente a las posibles amenazas externas o internas que desestabilicen el orden establecido" (Vega G, 2005. p. 2).

De este modo, la presencia de GAI (FARC y ELN), que han hecho blancos de oportunidad y fuente de recursos a la sociedad civil, generan un sentimiento de inseguridad que da paso a la percepción de un Estado vulnerable e incapaz de responder oportuna y contundentemente a este tipo de amenazas, punto en el cual la Fuerza Pública está llamada a intervenir para restablecer la confianza y tranquilidad de los ciudadanos, no obstante, en el presente caso, sus miembros también están expuestos a ser usados como generadores de mensajes políticos en los que subyace no solo la deslegitimación de las instituciones, sino también que ni siquiera ellos como portadores de las armas del Estado, en cualquier tiempo y lugar, son objetivos secuestrables.

Es de anotar que el ejemplo del secuestro de diplomáticos, ejecutivos de transnacionales, grandes empresarios, personas adineradas, políticos y servidores del Estado empezó en Argentina hacia mediados de la década de los 60, luego se extendió a Guatemala, Brasil, Paraguay $\mathrm{y}$, finalmente, llegó a Colombia. En todos los casos, los GAI de cada país aseguraban haber recurrido a este medio como forma de presión política hacia sus gobiernos opresores y para llamar la atención de la comunidad internacional acerca de las injusticias sociales que se cometían contra la población más vulnerable, de la cual ellos se asumían como sus representantes y defensores (Rubio. 2008. p. 9).

A esta modalidad de secuestro individual se sumó la de secuestros masivos, aplicando la ideología marxista-leninista exportada por el gobierno cubano después de hacerse con el poder, de recurrir a todas las formas de lucha para tratar de ganar imagen internacional sobre sus intereses, procurando propiciar golpes de opinión que atrajeran de inmediato la atención de los medios de comunicación y de la ciudadanía. Por ello y aprovechando la escasa vigilancia de los aeropuertos, primero el ELN, después las FARC e incluso el M-19, ejecutaron varios secuestros de aviones, algunos de ellos, como se verá a continuación, fueron desviados a Cuba,

6 de agosto de 1967, secuestro del Douglas DC-6 - HK-757 de Cóndor, en ruta BogotáSan Andrés. Cinco individuos fuertemente armados que decían pertenecer al ELN lo obligaron a desviarse hacia Cuba.

20 de Junio de 1.969 secuestro del HK-500 un DC-3 de La Urraca en ruta Monterrey y Aguazul (Casanare) por el ELN

30 de mayo de 1973, un Lockheed Electra L-188 HK-1274 de SAM, en ruta Cali Cartagena, llevado a Cuba por el ELN.

27 de enero de 1982 el HK-2637X de Aerotal, en ruta Bogotá-Pereira, fue secuestrado por un comando del M-19 autodenominado Héroes del Karina. Después de múltiples incidentes y el cambio de avión por destrucción parcial de la aeronave original debido a la intervención de la Fuerza Pública, los miembros del comando llegaron a Cuba.

12 de abril de 1999 el vuelo 9463 de Avianca fue secuestrado por seis guerrilleros del ELN, la mayoría de pasajeros fueron retenidos por un año en las selvas colombianas. 20 de febrero de 2002. Avión de AIRES 
desviado por las FARC para secuestrar al senador Jorge Eduardo Gechem Turbay" (Cifras y Conceptos, 2010, p. 1-2).

El secuestro de aviones junto con el de personas importantes en la vida nacional por parte de los GAI, representaron demostraciones de fuerza que implicaban un gran despliegue estratégico y logístico, lo cual no solo les dio la oportunidad de divulgar sus ambiciones de hacerse con el poder por medio de las armas, según el modelo cubano y lo que había ocurrido en países centroamericanos como Nicaragua, sino financiar sus operaciones con ingentes recursos económicos. Al respecto del secuestro como una fuente clave de ingresos, Jaime Bateman, líder del M-19 se refirió al mismo cuando relató:

(...) nosotros nos volvimos ricos realmente con la detención de Cooper, el gerente de Sears (...) Fue la primera vez que la organización tuvo un presupuesto bastante alto: más de un millón de dólares (...) Tal vez es el secuestro más grande que se ha hecho en Colombia, y el dinero nos alcanzó por mucho tiempo. Yo creo que todavía tenemos dinero de eso (Villamizar. 1995. p. 33).

Desde la década de los 80 en adelante, se puede hablar de una significativa profesionalización del secuestro con base en la prestación de los GAI, de servicios de vigilancia a los cultivos de coca, marihuana y amapola e incluso transporte de productos procesados, puesto que se requerían grandes recursos para conformar una infraestructura sólida destinada a cometer un delito de tan alto costo en términos económicos y transaccionales que incluían: la tecnología y la logística para llevar a cabo cada una de las etapas del delito, como por ejemplo: inteligencia, captura, movilización, manutención de las víctimas y la negociación, de tal manera que los GAI crearon unidades móviles especializadas que podían dedicarse a actividades o etapas específicas de la cadena delictiva (Krauthasen \& Sarmiento, 1991, p. 174).

Sin embargo, el discurso de conquistar el poder por las armas fue mutando progresivamente ante las diversas modalidades de crueldad y sometimiento con las que cosificaban a sus víctimas y familiares, obligando al Estado a modificar sus estrategias para enfrentarlos, por lo tanto, la imagen romántica que acompañó el surgimiento de las guerrillas dio paso al repudio generalizado de la sociedad, en consecuencia, retener a los miembros de la Fuerza Pública y presentarlos a modo de prisioneros de guerra, a los medios de comunicación nacionales e internacionales, fue considerado, particularmente por la dirigencia de las FARC, como la mejor opción para demostrar que su capacidad militar y de deslegitimación del gobierno continuaban vigentes. Esto sin dejar de lado las demás formas de secuestro, extorsión y chantaje, que ya venían practicando como fuente de financiación de sus actividades.

Como se ha podido observar, los GAI (FARC y ELN), consideran que retener a miembros de la Fuerza Pública le da mayor peso a sus argumentos políticos y cambia la perspectiva de la forma en que la sociedad civil ve sus acciones delincuenciales, puesto que creen aparecer como un ejército con elevado poder de beligerancia, ante el cual tanto el Estado como sus instituciones deben ceder y reconocerles en plano de igualdad, sus pretensiones de llegar al poder según un modelo político que desconoce el Estado Social de Derecho imperante en el país. Estas pretensiones desvirtúan lo expresado por los criminólogos de la Policía Nacional hacia 1964, cuando manifestaron que el secuestro era una de las características de la violencia tardía y anotaban que "los bandoleros principales dados de baja ese año habían aparecido implicados en varios de los secuestros" (Ortiz, 1985, p. 258), asumían por lo tanto, que el secuestro podía ser controlado y erradicado sin mayores complicaciones de la vida nacional, puesto que sus perpetradores estaban plenamente identificados y susceptibles de ser neutralizados por el gobierno, criterios que la historia se encargaría de negar en los siguientes años.

Con el paso del tiempo innumerables miembros de la Fuerza Pública, desde el surgimiento de los GAI a principios de la década de los 60, han sido el objetivo de atentados y ataques, causándoles a muchos de ellos heridas, desmembración y muerte, sin contar el trauma del secuestro y, en muchos casos, su desaparición. Este último fenómeno -considerando la cronología elaborada por diferentes organizaciones-, empieza a presentarse a partir de 1980; al menos así lo muestra la información recopilada por el autor en diferentes revistas de cobertura nacional 
(Semana); diarios de amplia distribución (El Tiempo; El Espectador; Vanguardia Liberal; El País; El Universal, El Mercurio, entre otros); Informes de HRW; FDLP, CNMH, entre otros y ONG nacionales e internacionales que corroboran o impugnan la magnitud de las cifras. A continuación se muestran los datos más relevantes:

Tabla 1. Síntesis de los casos en que ocurrieron secuestros y algunas masacres de miembros de la Fuerza Pública.

\begin{tabular}{|c|c|}
\hline 1980 & $\begin{array}{l}18 \text { de agosto: Al menos } 100 \text { hombres de las FARC copan en Puerto Crevo (a orillas del río Duda, } \\
\text { Meta) a una patrulla de } 20 \text { efectivos del Ejército. El ataque (denominado Cisne Tres por la } \\
\text { subversión) termina con } 3 \text { soldados muertos, } 3 \text { heridos y } 14 \text { secuestrados }\end{array}$ \\
\hline 1981 & $\begin{array}{l}20 \text { de octubre: Guerrilleros del M-19 secuestran un avión de Aeropesca en Medellín, y lo cargan } \\
\text { con armas en la Guajira. Finalmente lo hacen acuatizar en las selvas del sur. }\end{array}$ \\
\hline 1987 & $\begin{array}{l}22 \text { de marzo: Miembros del EPL atacan una patrulla de } 18 \text { policías antinarcóticos en Necoclí } \\
\text { (Antioquia). } 11 \text { uniformados mueren y } 3 \text { más son secuestrados }\end{array}$ \\
\hline 1988 & $\begin{array}{l}23 \text { de agosto: Al menos } 300 \text { subversivos de las FARC y el EPL, atacan el pueblo de Saiza (Córdoba). } \\
\text { Después de } 12 \text { horas de combate, se reportaron } 51 \text { muertos ( } 12 \text { soldados, } 2 \text { policías, } 12 \text { civiles } \\
\text { y } 25 \text { guerrilleros) y } 22 \text { miembros de la fuerza pública secuestrados. }\end{array}$ \\
\hline 1989 & $\begin{array}{l}25 \text { de mayo: La Ley } 48 \text { de 1968, que permite a las FF.MM. patrocinar la conformación de grupos } \\
\text { de autodefensa, es declarada inconstitucional por la Corte Suprema de justicia. }\end{array}$ \\
\hline 1990 & $\begin{array}{l}22 \text { de febrero: Guerrilleros de las FARC y el EPL, atacan un puesto de patrullaje móvil del } \\
\text { Batallón Bombona en Segovia (Antioquia). Mueren } 7 \text { soldados y } 14 \text { más son secuestrados. }\end{array}$ \\
\hline 1991 & $\begin{array}{l}8 \text { de Enero: Miembros de las FARC se toman el cerro Girasol de Mesetas (Meta), en represalia } \\
\text { por la destrucción de Casa Verde. Guarnecido por } 41 \text { soldados, } 2 \text { de ellos mueren y } 17 \text { son } \\
\text { secuestrados en el asalto, que también le cuesta la vida a } 30 \text { subversivos. }\end{array}$ \\
\hline 1994 & $\begin{array}{l}9 \text { de agosto: Es copado por las FARC el cuartel de la Policía de Cartagena del Chaira (Caquetá). } \\
\text { El saldo es de } 4 \text { uniformados muertos y } 5 \text { secuestrados. El mismo día cae asesinado en Bogotá, } \\
\text { el senador de la UP, Manuel Cepeda Vargas. }\end{array}$ \\
\hline 1996 & $\begin{array}{l}30 \text { de agosto - } 31 \text { de agosto: Guerrilleros de las FARC atacan la base militar de "Las Delicias", en } \\
\text { el Putumayo. Una compañía de soldados regulares es copada: } 27 \text { muertos y } 60 \text { secuestrados. }\end{array}$ \\
\hline 1997 & $\begin{array}{l}16 \text { de enero: Guerrilleros de las FARC atacan un puesto de la infantería de marina en Coredo, } \\
\text { Jurado (Choco). Tres infantes de marina mueren y } 10 \text { más son capturados } \\
21 \text { de diciembre: Las FARC atacan una base del Ejército en el cerro de Patascoy, suroeste de } \\
\text { Colombia cerca de la frontera con el Ecuador. Mueren } 11 \text { militares y } 18 \text { son secuestrados. }\end{array}$ \\
\hline 1998 & $\begin{array}{l}\text { 1-3 de marzo: Un ataque en El Billar (Caquetá) deja } 64 \text { militares muertos y } 43 \text { secuestrados. El } \\
\text { Batallón Contraguerrilla No } 52 \text { de la Brigada Móvil } 3 \text { (153 soldados) es destruido. Es la mayor } \\
\text { derrota del ejército en el conflicto. } \\
3 \text { de agosto- } 4 \text { de agosto: Ofensiva de «despedida al Gobierno Samper». Guerrilleros de las } \\
\text { FARC y el ELN, atacaron en todo el país } 62 \text { objetivos del Gobierno con asaltos masivos de } \\
\text { instalaciones militares, hostigamientos, sabotajes y carros bomba, dejando } 81 \text { uniformados } \\
\text { muertos, } 120 \text { heridos y más de } 150 \text { secuestrados. } \\
3 \text { y } 4 \text { de agosto: Las FARC atacan una base antinarcóticos en Miraflores (Guaviare), matan a } 16 \\
\text { policías y militares y secuestran a } 129 \text {. } \\
3 \text { de agosto- } 4 \text { de agosto: } 500 \text { guerrilleros de los frentes } 5,18,34,57 \text { y } 58 \text { de las FARC, atacan un } \\
\text { pelotón de } 36 \text { soldados regulares adscritos al Batallón Voltígeros de la Brigada } 17 \text { del Ejercito, } \\
\text { en Pavarandó (Urabá antioqueño). En el ataque perecieron } 14 \text { soldados, } 14 \text { quedaron heridos } \\
\text { y } 9 \text { fueron secuestrados. } \\
14 \text { de agosto: En Tamborales (Riosucio, Choco) se produce una batalla campal entre } 200 \\
\text { soldados del batallón de contraguerrillas No } 11 \text { Cacique Coyara que pretendía rescatar a los } \\
\text { secuestrados de Paravandó, y } 800 \text { irregulares de los frentes } 5,18,34 \text { y } 57 \text { de las FARC. }\end{array}$ \\
\hline
\end{tabular}




\begin{tabular}{|c|c|}
\hline & $\begin{array}{l}\text { Como resultado del combate perdieron la vida } 42 \text { militares y } 21 \text { más fueron secuestrados, } \\
\text { mientras los subversivos contaron más de medio centenar de muertos. } \\
12 \text { de septiembre: } 300 \text { guerrilleros de las FARC, el EPL y el ELN asaltan el corregimiento de Las } \\
\text { Mercedes en Norte de Santander, secuestrando a los } 20 \text { uniformados que ocupaban el cuartel } \\
\text { de policía. } \\
1 \text { de noviembre: La guerrilla de las FARC ocupa Mitú, capital del departamento de Vaupés. } \\
\text { Mueren } 16 \text { policías y } 61 \text { más son secuestrados. }\end{array}$ \\
\hline \multirow{4}{*}{1999} & $\begin{array}{l}25 \text { de febrero: Los indigenistas estadounidenses Terence Freitas, Lahenaee Gay e Ingrid } \\
\text { Washinawatok son secuestrados por las FARC en una región fronteriza entre Colombia y } \\
\text { Venezuela }\end{array}$ \\
\hline & $\begin{array}{l}13 \text { de marzo: Los Bloques José María Córdoba y Caribe de las FARC entregan la lista de } 61 \\
\text { canjeables entre los que figuran políticos, militares y policías secuestrados, para un eventual } \\
\text { acuerdo humanitario. }\end{array}$ \\
\hline & $\begin{array}{l}19 \text { de marzo: Familiares de } 320 \text { soldados y policías secuestrados por las FARC se toman las } \\
\text { instalaciones del Congreso de Colombia para pedirle al gobierno que logre su liberación. }\end{array}$ \\
\hline & $\begin{array}{l}5 \text { de abril: Secuestrados el coronel de la Policía Álvaro León Acosta, comandante del distrito } \\
\text { de Palmira, y } 3 \text { uniformados más, cuando su helicóptero es derribado en Barragán, zona rural } \\
\text { de Tuluá (Valle). }\end{array}$ \\
\hline \multirow{7}{*}{2000} & $\begin{array}{l}5 \text { de enero: Diez mil campesinos de Santa Rosa y Simití, de Bolívar, marcharon contra la } \\
\text { posibilidad de que el Gobierno Nacional autorice despejar municipios para que el ELN realice } \\
\text { una convención nacional }\end{array}$ \\
\hline & $\begin{array}{l}29 \text { de enero: Comienzan oficialmente las negociaciones entre el gobierno y las FARC. Los } \\
\text { medios de comunicación no van al encuentro por el secuestro del director de un noticiero de } \\
\text { televisión }\end{array}$ \\
\hline & $\begin{array}{l}24 \text { de marzo: Las FARC atacan la población de Vigía del Fuerte, departamento de Antioquia } \\
\text { asesinando o secuestrando a miembros de las fuerza pública, además de masacrar a } 8 \text { civiles }\end{array}$ \\
\hline & $\begin{array}{l}16 \text { de mayo: El Gobierno suspende reunión que diplomáticos de varios países tenían concertada } \\
\text { con las FARC. El presidente Pastrana acusó a las FARC de colocar un collar-bomba que mató a } \\
\text { dos personas }\end{array}$ \\
\hline & 5 de diciembre. Este año las fuerzas de las FARC se estiman en 17.000 combatientes \\
\hline & $\begin{array}{l}23 \text { de diciembre: En un acto de "buena voluntad", la guerrilla del ELN libera a } 42 \text { soldados y } \\
\text { policías que mantenía secuestrados. }\end{array}$ \\
\hline & $\begin{array}{l}29 \text { de diciembre: El legislador colombiano Diego Turbay Cote, líder del comité de paz el Congreso } \\
\text { es asesinado con otras cinco personas en una carretera del departamento del Caquetá por las } \\
\text { FARC. }\end{array}$ \\
\hline \multirow{3}{*}{2001} & $\begin{array}{l}19 \text { de abril: El ELN liberó a } 34 \text { trabajadores de la petrolera Occidental (Oxy) secuestrados. } \\
\text { Fueron entregados al Comité Internacional de la Cruz Roja (CICR) }\end{array}$ \\
\hline & $\begin{array}{l}28 \text { de junio: Los gobiernos de Estados Unidos y Colombia aseguran que las FARC han utilizado } \\
\text { la zona de distensión para rearmarse, preparar atentados, ocultar secuestrados y traficar con } \\
\text { drogas ilegales. Critican el show por la liberación, en La Macarena, de } 242 \text { soldados y policías } \\
\text { secuestrados para presionar al gobierno a un supuesto acuerdo humanitario. }\end{array}$ \\
\hline & $\begin{array}{l}12 \text { al } 15 \text { de diciembre: el gobierno colombiano y el ELN se reúnen en La Habana, en la primera } \\
\text { ronda de trabajo bilateral convenida en el Acuerdo por Colombia, para buscar una la solución } \\
\text { política al conflicto interno armado. Dan a conocer la llamada "Declaración de La Habana". }\end{array}$ \\
\hline 2002 & $\begin{array}{l}20 \text { de febrero: Guerrilleros de las FARC obligaron al piloto de un avión de AIRES a aterrizar en } \\
\text { una carretera del Huila y secuestran a tres ocupantes, entre ellos el senador Jorge Eduardo } \\
\text { Gechem Turbay, lo que provoca la ruptura de los diálogos de paz del Caguán entre el gobierno } \\
\text { Pastrana y las FARC. }\end{array}$ \\
\hline
\end{tabular}




\begin{tabular}{|c|c|}
\hline 2003 & $\begin{array}{l}13 \text { de febrero: Las FARC secuestran a los estadounidenses Keith Stansell, Marc Gonsalves y } \\
\text { Thomas Howes tras la caída de la avioteta en la que viajaban en sobre el departamento del } \\
\text { Caquetá. }\end{array}$ \\
\hline \multirow{2}{*}{2004} & $\begin{array}{l}14 \text { de septiembre: Las FARC proponen despejar militarmente las localidades de Cartagena del } \\
\text { Chairá y San Vicente del Caguán, en el departamento del Caquetá, para negociar un canje de } \\
\text { rehenes por guerrilleros presos, pero Uribe descarta la propuesta. }\end{array}$ \\
\hline & $\begin{array}{l}28 \text { de noviembre: En otra propuesta, las FARC piden despeje militar de Florida y Pradera en } \\
\text { el Valle para negociar el intercambio humanitario, opción descartada por el Gobierno Uribe. }\end{array}$ \\
\hline \multirow{8}{*}{2005} & $\begin{array}{l}26 \text { de enero: Las FARC atacan la cárcel de Picaleña en Ibagué, Tolima y liberan guerrilleros } \\
\text { presos. }\end{array}$ \\
\hline & 1 de febrero: Las FARC asesinan a 17 Infantes de Marina en el municipio de Iscuandé \\
\hline & 5 de febrero. Se estima que las FARC poseen 17.000 hombres y el ELN 4.000. \\
\hline & $\begin{array}{l}9 \text { de febrero Las FARC atacan y asesinan a } 19 \text { policías en inmediaciones de Mutatá, en la región } \\
\text { del Urabá }\end{array}$ \\
\hline & $\begin{array}{l}25 \text { de junio: El Frente } 48 \text { de las FARC combate contra tropas del Batallón Plan Energético y Vial } \\
\text { No.1 instalado en la Base militar de Teteyé. La incursión provocó la muerte de } 19 \text { militares, } \\
\text { otros } 11 \text { fueron heridos y uno secuestrado }\end{array}$ \\
\hline & $\begin{array}{l}25 \text { de junio se confirma el fin de la desmovilización de las AUC. Entre abril } 25 \text { de } 2004 \text { y julio } \\
20 \text { de 2005, unos } 31.671 \text { paramilitares son desmovilizados. }\end{array}$ \\
\hline & $\begin{array}{l}17 \text { de diciembre: En el caserío de San Marino, departamento del Chocó, las FARC asesinaron a } \\
\text { ocho policías y secuestran a } 30 \text {. Son liberados tres días más tarde. }\end{array}$ \\
\hline & $\begin{array}{l}28 \text { de diciembre: En el corregimiento de Playa Rica, municipio de Vistahermosa, en el } \\
\text { departamento del Meta, la guerrilla de las FARC atacó un grupo de soldado que patrullaba la } \\
\text { erradicación de cultivos ilícitos. } 24 \text { soldados y cinco guerrilleros murieron. }\end{array}$ \\
\hline \multirow[t]{2}{*}{2006} & $\begin{array}{l}27 \text { de febrero: En un acto de sabotaje la Columna Móvil Teófilo Forero de las FARC a las } \\
\text { Elecciones presidenciales de Colombia de 2006, nueve concejales fueron masacrados en Rivera } \\
\text { mientras sesionaban en un hostal ubicado en el casco urbano del municipio }\end{array}$ \\
\hline & $\begin{array}{l}22 \text { de mayo: El "Batallón de Alta Montaña" del ejército de Colombia (cuerpo élite), comandado } \\
\text { por el coronel Byron Carvajal comete la Masacre de Jamundí en el municipio de Jamundí, Valle. }\end{array}$ \\
\hline \multirow{6}{*}{2007} & $\begin{array}{l}28 \text { de abril: El policía Jhon Frank Pinchao, secuestrado en noviembre de } 1998 \text { durante las Toma } \\
\text { de Mitú por las FARC, es rescatado en el Vaupés tras huir por la selva durante } 17 \text { días. }\end{array}$ \\
\hline & $\begin{array}{l}25 \text { de mayo: El presidente Álvaro Uribe anuncia la excarcelación masiva de guerrilleros por } \\
\text { "razones de Estado" y la liberación del guerrillero de las FARC, alias "Rodrigo Granda", por } \\
\text { petición del presidente francés, Nicolas Sarkozy, para que haga "gestiones de paz" }\end{array}$ \\
\hline & $\begin{array}{l}1 \text { de junio: el gobierno del presidente Uribe prepara una excarcelación masiva de guerrilleros } \\
\text { de las FARC. Cerca de } 1200 \text { guerrilleros fueron postulados y serían liberados en el municipio } \\
\text { boyacense de Chiquinquirá. La excarcelación incluye al 'canciller de las FARC', Rodrigo Granda } \\
\text { que quedará en libertad pero no recibirá indulto. }\end{array}$ \\
\hline & $\begin{array}{l}28 \text { de junio: Las FARC informan que el } 18 \text { de junio, murieron once de los doce diputados del } \\
\text { Valle del Cauca en "fuego cruzado" con un grupo militar no identificado. }\end{array}$ \\
\hline & $\begin{array}{l}29 \text { de agosto: La Policía frustró dos planes que iban a ser ejecutados por guerrilleros de la } \\
\text { Columna Móvil Teófilo Forero de las FARC. Según el Gen. Óscar Naranjo, planeaban asesinar } \\
\text { a un grupo de asesores militares estadounidenses del Plan Colombia, que vivían en Melgar, } \\
\text { Tolima. También pretendieron realizar un secuestro masivo en un edificio de Armenia, similar } \\
\text { al edificio Miraflores de Neiva. }\end{array}$ \\
\hline & $\begin{array}{l}30 \text { de diciembre: La guerrillas de las FARC intentaron derribar un avión militar que despegaba } \\
\text { del Aeropuerto Benito Salas de la ciudad de Neiva. }\end{array}$ \\
\hline
\end{tabular}




\begin{tabular}{|c|c|}
\hline \multirow{5}{*}{2008} & $\begin{array}{l}10 \text { de enero - Las FARC liberan a Clara Rojas y Consuelo González de Perdomo en el marco de } \\
\text { la denominada Operación Emmanuel. }\end{array}$ \\
\hline & $\begin{array}{l}4 \text { de febrero - Miles de personas marchan en todas las ciudades rechazando las acciones } \\
\text { de las FARC, a las que agregan las marchas alrededor del mundo contra los terroristas y } \\
\text { narcoterroristas sumando } 12 \text { millones de manifestantes. }\end{array}$ \\
\hline & $\begin{array}{l}1 \text { de marzo - Operación Fénix: la FAC bombardea un campamento de las FARC en territorio } \\
\text { ecuatoriano dando muerte a Raúl Reyes e iniciando una crisis diplomática por haber violado } \\
\text { su soberanía. }\end{array}$ \\
\hline & $\begin{array}{l}2 \text { de julio - Operación Jaque. El Ejército de Colombia logra la liberación de Ingrid Betancourt } \\
\text { tres norteamericanos, siete soldados y cuatro policías que permanecían secuestrados en poder } \\
\text { de las FARC }\end{array}$ \\
\hline & $\begin{array}{l}31 \text { de agosto: atentado al Palacio de Justicia de Cali. El coche bomba, cargado con } 80 \text { kilos } \\
\text { de explosivos, destruyó parte del primer piso del edificio causando la muerte de } 4 \text { personas } \\
\text { y dejando } 26 \text { heridas. El gobierno culpó al Frente Manuel Cepeda Vargas de las FARC del } \\
\text { atentado. }\end{array}$ \\
\hline \multirow{11}{*}{2009} & $\begin{array}{l}2 \text { de enero: La senadora Piedad Córdoba, anuncia que las FARC liberarán a seis secuestrados; } \\
\text { tres agentes de la Policía, un soldado y los políticos Alan Jara y Sigifredo López. }\end{array}$ \\
\hline & $\begin{array}{l}8 \text { de enero: Es ascendido a General, el Coronel Luis Mendieta, secuestrado por las FARC durante } \\
\text { la toma de Mitú }\end{array}$ \\
\hline & $\begin{array}{l}2 \text { de febrero: Tras una Operación humanitaria son liberados los policías Walter José Lozano } \\
\text { Guarnizo, Juan Fernando Galicia Uribe y Alexis Torres Zapata, y el soldado profesional William } \\
\text { Giovanni Domínguez, secuestrados por las FARC. }\end{array}$ \\
\hline & $\begin{array}{l}3 \text { de febrero: En la Operación humanitaria, las FARC liberaron al ex gobernador del Meta Alan } \\
\text { Jara. }\end{array}$ \\
\hline & 4 de febrero: Las FARC Masacran 17 indígenas Awá en el departamento de Nariño. \\
\hline & $\begin{array}{l}5 \text { de febrero: Como la última fase de la Operación humanitaria, las FARC liberaron al diputado } \\
\text { del Valle Sigifredo López. }\end{array}$ \\
\hline & $\begin{array}{l}27 \text { de febrero: El Ejército lleva a cabo la Operación Fuerte, en el páramo de Sumapaz y suprime } \\
\text { una ofensiva de las FARC en Cundinamarca, denominada Plan Renacer, para bloquear a la } \\
\text { capital, Bogotá. }\end{array}$ \\
\hline & $\begin{array}{l}25 \text { de Junio. Se cree que las FARC posern } 6.000 \text { a } 7.000 \text { combatientes. Otras fuentes estiman } \\
\text { que la cantidad de niños-soldado usados por esta guerrilla es de } 14 \text { a } 17 \text { mil (tres años atrás } \\
\text { eran } 6 \text { a } 11 \text { mil), tratando de reemplazar las altas bajas y deserciones que ha sufrido en los } \\
\text { últimos años. }\end{array}$ \\
\hline & $\begin{array}{l}29 \text { de junio.- Las FARC promete entregar a una comisión encabezada por Piedad Córdoba a } \\
\text { Josué Daniel Calvo, secuestrado el } 20 \text { de abril de } 2009 \text { en el Meta, y los restos del capitán Julián } \\
\text { Guevara, muerto en la selva en } 2006 \text { tras ocho años de secuestro }\end{array}$ \\
\hline & $\begin{array}{l}7 \text { de diciembre: La Columna Móvil Teófilo Forero de las FARC atenta contra el Club Los } \\
\text { Andaquíes de la ciudad de Neiva. }\end{array}$ \\
\hline & $\begin{array}{l}22 \text { de diciembre: El gobernador del Caquetá, Luis Francisco Cuéllar fue asesinado por miembros } \\
\text { de la Columna Móvil Teófilo Forero de las FARC. }\end{array}$ \\
\hline \multirow[b]{2}{*}{2010} & $\begin{array}{l}4 \text { de noviembre: En un operativo del ejército fue abatido el máximo jefe de las FARC, alias } \\
\text { Alfonso Cano. }\end{array}$ \\
\hline & $\begin{array}{l}26 \text { de noviembre: El sargento Libio José Martínez y otros tres sargentos secuestrados son } \\
\text { asesinados por guerrilleros de las FARC tras un intento de rescate por el ejército de Colombia, } \\
\text { mientras que el sargento Luis Erazo sobrevivió a la masacre. }\end{array}$ \\
\hline
\end{tabular}




\begin{tabular}{|c|c|}
\hline \multirow{3}{*}{2011} & $\begin{array}{l}31 \text { de mayo: Es liberado el periodista francés Roméo Langlois tras un secuestro de } 33 \text { días por } \\
\text { las FARC }\end{array}$ \\
\hline & $\begin{array}{l}18 \text { de octubre: Se inician las conversaciones de proceso de paz en Oslo, reuniendo al gobierno } \\
\text { colombiano y las FARC para buscar una salida al conflicto armado. }\end{array}$ \\
\hline & $\begin{array}{l}7 \text { de diciembre. Marchas en todo el país, vestidos de blanco, por la liberación de los secuestrados } \\
\text { por las Farc. Algunos llevan más de } 10 \text { años de secuestrados. }\end{array}$ \\
\hline \multirow{4}{*}{2012} & $\begin{array}{l}1 \text { de enero: Mueren } 13 \text { guerrilleros de las FARC en un bombardeo de la FAC cerca de la frontera } \\
\text { con Panamá. }\end{array}$ \\
\hline & $\begin{array}{l}5 \text { de abril: Cuatro militares colombianos murieron durante los combates con las FARC en el } \\
\text { norte de Cauca. }\end{array}$ \\
\hline & $\begin{array}{l}26 \text { de mayo: El gobierno y las FARC anuncian avances en los diálogos de paz que se adelantan } \\
\text { en La Habana. }\end{array}$ \\
\hline & $\begin{array}{l}6 \text { de noviembre: El gobierno y las FARC anuncian el acuerdo sobre participación política en los } \\
\text { diálogos de paz que se adelantan en La Habana. }\end{array}$ \\
\hline
\end{tabular}

Fuente: Elaboración propia con base en consulta de diferentes fuentes oficiales y privadas.

En la Tabla 1 se observa, por una parte, que el secuestro de policías y militares no ha sido un asunto ocasional y que alcanzó entre 1980 y 2012 cifras equivalentes a las de una guerra de grandes proporciones, por otra, que en el año de 1998, las FARC golpearon durante a la Fuerza Pública, causándole no solo bajas mortales y heridos, sino secuestrando el mayor número de integrantes conocidos, hasta el punto de tener que someterlos en verdaderos campos de concentración en la selva, bajo condiciones infrahumanas.

El presidente de la época, ante la violación de los DDHH, la infracción del DIH y la incapacidad en ese momento de la Fuerza Pública para enfrentar un desafío de ese tamaño, solicitó un mayor apoyo de los EE.UU. en recursos y capacitación de las fuerzas en el esquema del llamado Plan Colombia, pero la respuesta positiva solo se hizo efectiva en el gobierno del siguiente presidente, permitiendo realizar ajustes profundos en la estrategia y empezar a golpear duramente a los GAI en todo el territorio nacional, diezmándolos donde se detectaban sus reductos.

Mientras tanto, el discurso institucionalizado de policías y militares permanece centrado, siguiendo a Merlau-Ponty, alrededor de "cuerpos hablantes y hablados, transmisores y receptores, activos y actuados, en un juego de interrelación que se da tanto consigo mismo como con el otro" (Crossley, 1995, p. 51), lo que es equivalente a decir, cuerpos expuestos en todo momento a que la expresión de sus gestos alcance niveles ponderados o excesivos de violencia institucionalizada, afirmando o debilitando el compromiso y autoridad confiada a ellos por el Estado, en aras de la defensa de las instituciones democráticamente establecidas, no obstante, en su calidad de víctimas resultan parte de la estadística general, con la simple mención de uniformados caídos, heridos, desmembrados o secuestrados en combate.

Al mismo tiempo pocas son las menciones de lo que ocurre a nivel del drama familiar y menos entendible la paradoja con respecto a la "reparación integral de los miembros de la fuerza pública, reconocida por la Ley 1448 de 2011- toda vez que frente a la reparación integral, (...) encuentra escollos al sujetar la reparación económica al régimen especial que le es propio" (Mejía A. \& Marín R. 2015b. p. 74), dicho de otro modo, aunque el militar y el policía en su condición de víctima del conflicto armado interno tiene los mismos derechos que un civil, debe enfrentar un proceso menos expedito para recibir los beneficios que le otorga la ley, al estar subsumidos en gran medida a los trámites propios de su régimen prestacional.

Por su parte, el discurso de la sociedad civil es tanto o más silencioso y permeado por intereses políticos con amigos y detractores, reduciéndose en algunas ocasiones a marchas de rechazo a las acciones terroristas, aparatosas en cartelones, fotos y banderas, aunque usualmente con poco despliegue en los medios, por no ser una noticia 
sensacionalista que contribuya a incrementar el tiraje de revistas o periódicos. Por eso sus efectos para elevar el grado de sensibilidad frente a la violencia de los GAI, y su persistente violación de los DDHH e infracción del DIH, no genera las transformaciones requeridas en los imaginarios colectivos para crear un frente fuerte y unido que muestre a los violentos una sociedad decidida a no permitir la repetición de sus acciones.

Como se puede deducir, las cifras de militares y policías secuestrados no son exactas y algunas fuentes, como el $\mathrm{CNMH}$, reconocen que a este respecto ha habido hermetismo por parte del Estado, a pesar de que las estimaciones de dichas cifras entre 1980 y 2002, están entre 550 y 650 militares, policías, infantes de marina y personal auxiliar, además de heridos, muertos y desaparecidos en números que solo pueden darse en presencia de una guerra total.

Son de especial mención algunos aspectos claves en relación con el fenómeno del secuestro de policías y militares, el primero es la contradicción constante entre el discurso del gobierno nacional con respecto a las cifras que hablan de una reducción del secuestro y los resultados de algunas organizaciones oficiales y privadas a favor y en contra de las mismas. El segundo es cómo, no por generosidad de las FARC, se dio por terminado el infame espectáculo de miembros de la Fuerza Pública encerrados en verdaderos campos de concentración montados en la selva colombiana.

El tercero, corresponde al ejemplo dado a las demás fuerzas por el Ejército Nacional, de acuerdo con la Directiva 078, de 2012, mediante la cual se dio inicio a un proceso de visibilización de las víctimas militares y sus familiares, buscando "realizar un censo a partir del 26 de abril de 2013, emitiéndose cronogramas para lograr el registro, iniciando con la participación del personal del Centro Nacional de Artefactos explosivos improvisados (Cenam), cuya actividad obtuvo un registro de 219 víctimas militares" (Mejía A. \& Marín R. 2015b. p, 75).

El cuarto, la victimación en general de la que han sido objeto los familiares de militares y policías afectados por el conflicto armado interno. A este respecto el artículo $2^{\circ}$ de la Ley 1592 de 2012, modificó el artículo 5o de la Ley 975 de 2005, e introdujo con total claridad la definición declarada exequible por la Corte Constitucional mediante la cual además del militar o policía victimizado:

(...) se tendrán como víctimas al cónyuge, compañero o compañera permanente $y$ familiares en primer grado de consanguinidad, de los miembros de la fuerza pública que hayan perdido la vida en desarrollo de actos del servicio, en relación con el mismo, o fuera de él, como consecuencia de los actos ejecutados por algún miembro de los grupos armados organizados al margen de la ley (Corte Constitucional, 2013).

Adicionalmente afirma la Corte:

(...) también se tendrán como víctimas a los familiares en primer grado civil de los miembros de la fuerza pública que hayan perdido la vida en desarrollo de actos del servicio, en relación con el mismo, o fuera de él, como consecuencia de los actos ejecutados por algún miembro de los grupos armados organizados al margen de la ley (Corte Constitucional, 2013).

Tal afirmación ha recorrido un largo camino para consolidarse como una posición jurídica justa y acorde con la realidad de la persona humana de los miembros de la Fuerza Pública al mismo nivel de la población civil, incluso: “... la refriega judicial más dura que se ha vivido en los últimos cincuenta años en materia de Derechos Humanos de los miembros de las FF.AA., la constituye el desconocido episodio de las demandas a la Ley 975 de 2005, en cuanto a la inclusión de los miembros de las FF.AA. cómo víctimas del conflicto armado" (Mejía, 2013aㅡ, p. 11-12), desconocimiento más llamativo pues las voces en contra no provenían de la sociedad civil.

Sin lugar a dudas detrás de dicha negativa estaban organizaciones de DDHH y muchos amigos de los GAI, que llegaron a demandar el artículo 5을 de la Ley 975 de 2005 alegando que:

a). En ninguna norma del DI de los DD.HH. se incluía a los miembros de las FF.AA. como víctimas, por tanto, el legislativo violentaba el bloque de constitucionalidad y la primacía del DI, al incluir a los militares y policías como víctimas del conflicto armado.

(b). Los militares y policías al ser miembros de la Fuerza Pública detentan por determinación 
constitucional el monopolio de la fuerza. En razón de lo anterior, la vocación de los miembros de las FF.AA., es la de ser victimarios y no víctimas, pues ostentan la posición de garante, están subordinados a relaciones especiales de sujeción y además comprometen la responsabilidad del Estado por violaciones de DD.HH (Mejía, 2013a, p. 11-12).

Un análisis rápido de la síntesis de los alegatos anteriores muestra la intención de invisibilizar a los miembros de la Fuerza Pública, negándoles su derecho a ser considerados víctimas del conflicto armado interno $y$, por el contrario, afirmando que las víctimas son quienes han sometido a la sociedad colombiana a los efectos perniciosos del narcoterrorismo, el secuestro, la extorsión, los atentados en áreas urbanas y rurales contra quienes defienden la institucionalidad del país. Es por ello que la Corte Constitucional en sentencias C-575 del 2006 y C-080 del 2007,

utilizando el principio pro homine (aplicación de la norma más favorable al ser humano), declaró ajustado a la Constitución el que militares, policías y núcleo familiar así como esposa o esposo, compañera o compañero permanente sean víctimas del conflicto armado, convirtiéndose en términos reales en el precedente jurisprudencial más importante para la Fuerza Pública desde la creación de la jurisdicción constitucional en 1991 (Mejía, 2013a, p. 11-12).

Esta doble afirmación de la Corte Constitucional fortaleció el piso jurídico de la Ley 975 de 2005 en cuanto al reconocimiento del derecho de los miembros de la Fuerza Pública y sus familiares a las "medidas de atención, asistencia y reparación integral a las víctimas del conflicto armado interno", como reza el encabezado de la Ley 1448 de 2011, razón por la cual la jurisprudencia creada frenó el desconocimiento que se pretendía impulsar desde los sectores afectos a los GAI. Al respecto el artículo $3^{\circ}$ va más allá de la legislación existente en la materia, como se muestra a continuación:

Artículo $3^{\circ}$. Víctimas. Se consideran víctimas, para los efectos de esta ley, aquellas personas que individual o colectivamente hayan sufrido un daño por hechos ocurridos a partir del 1 o de enero de 1985, como consecuencia de infracciones al Derecho Internacional Humanitario o de violaciones graves $y$ manifiestas a las normas internacionales de Derechos Humanos, ocurridas con ocasión del conflicto armado interno. (Ley 1448 de 2011) Nota: El texto subrayado fue declarado Exequible por la Corte Constitucional mediante (Sentencia C-250 de 2012).

Nota: El texto en cursiva declarado Exequible por la Corte Constitucional mediante (Sentencia C-280 de 2013).

Es importante tomar en consideración que el Artículo 3o de la Ley 1448 de 2011, demanda una nueva epistemología en cuanto "toda infracción al DIH tiene relación con el conflicto armado interno pues no se puede aplicar este cuerpo normativo por fuera de él, debe mirarse, sin embargo, desde una perspectiva de justicia transicional colombiana más evolucionada" (Mejía, 2013a, p. 13).

\section{CONTEXTO DEL CONFLICTO ARMADO COLOMBIANO}

Es habitual que los GAI, a pesar de ser uno de los promotores del fenómeno del secuestro en Colombia, se conciban como agentes de cambio social cuando afirman ser el ejército del pueblo.

La proliferación de organizaciones subversivas, más las bandas del crimen organizado, resultaron clave para la intensificación del secuestro en diferentes lugares del país. Mientras en los años 60 solo se conocían casos aislados como los de la familia Eder y algunas personas adineradas, con el tiempo dejó de ser algo casual para convertirse en un fenómeno sistemático, como una aplicación de los principios marxistas-leninistas y marxistasmaoístas de recurrir a cualquier forma de lucha para financiar sus actividades con miras a tomarse finalmente el poder político (Caballero, 2013, p. 6-7).

Esta concentración y dispersión de GAI, autoproclamados como insurgentes, incidieron para que el fenómeno del secuestro extorsivo adquiriera unas connotaciones de gravedad social, económica y política, nunca antes vistas. Según Caballero (2013) sus blancos fueron "los ejecutivos de las multinacionales, ganaderos, hombres de familias reconocidas en la región, diplomáticos, líderes religiosos y políticos" (p. 18-19). En el año 1985, cuando la guerrilla Movimiento 19 de Abril (M-19), llevó a cabo la toma del Palacio de Justicia en Bogotá, “donde murieron más rehenes que 
combatientes" (El Espectador, 2013), quedó develado el verdadero carácter de los GAI en cuanto a su indiscriminada capacidad para llamar la atención mediante actos terroristas.

7000 víctimas denunciadas entre 1964-1990 y luego más de mil secuestros por año, cifra que con el tiempo llegó a triplicarse. Por eso, Francisco Santos, después de ser liberado por las FARC y a través de su Fundación País Libre, logró mediante recolección de firmas promover la expedición de la Ley 40 de 1993 o más conocida como el Estatuto Nacional contra el Secuestro.

A partir de 1996 las cifras muestran que los secuestros no se detienen "pues son reportados 1398 casos, incluso fue secuestrado el hermano del presidente César Gaviria y liberado ocho meses más tarde (Caballero. 2013. p. 19).

Igualmente añade Caballero (2013), que entre los años 2000 y 2007, fueron secuestradas 14.676 personas, de los cuales "1933 solo durante el año 2013 aparecen todavía como secuestrados, desconociéndose si están vivos o muertos enterrados en fosas comunes o en algún camposanto como NN" (p. 19). En este mismo sentido se afirma que de "3307 casos denunciados hasta 2009 como secuestrados en cautiverio, solo podían establecer que 507 habían quedado libres o fallecidos en manos de sus captores” (Henao, 2013).

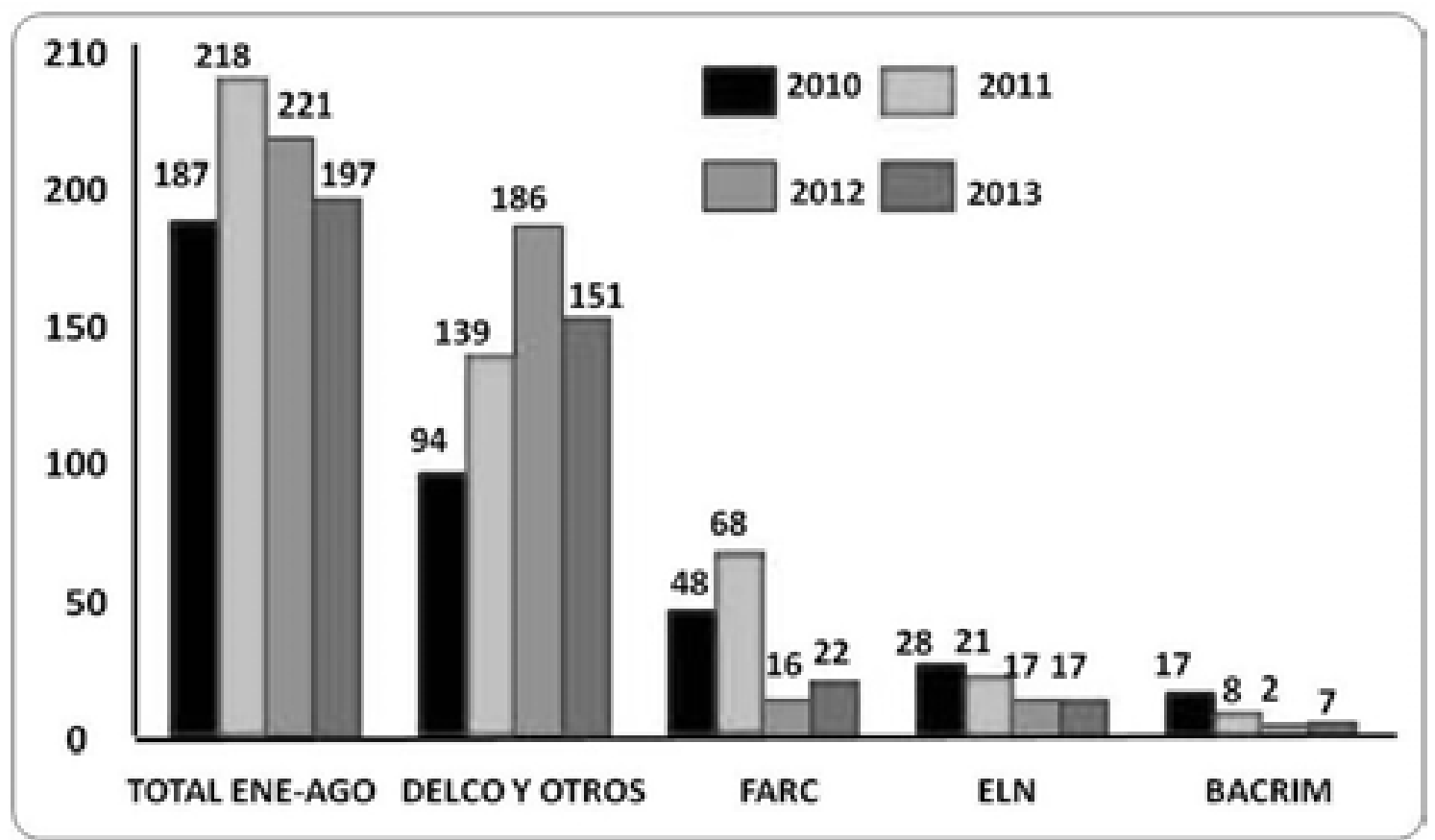

Figura 1. Secuestro general por autor: Comparativo enero-agosto 2010-2013.

Fuente. FDLP y Ministerio de Defensa Nacional. Fecha de corte agosto 8 de 2013.

En la figura 1, como indican las barras donde se agrupan los grupos de delincuencia común Delcom y otros, el peso del secuestro pareciera concentrarse en ellos, pero no se muestra, por la dificultad para hacerlo, el desglose de cuántas personas civiles o miembros de la Fuerza Pública y funcionarios del Estado, incluyendo los de elección popular, han caído en poder de los GAI, bien sea por su accionar directo o prestando servicios de inteligencia, logístico u operativo, tanto en las áreas urbanas como rurales. Además, la Delcom, por estar insertada entre la población civil, vende información a los GAI facilitándoles el éxito de sus golpes criminales, en especial, contra unidades militares y de policía.

Es evidente que la complejidad estadística del delito del secuestro, persiste hasta el presente sin claridad sobre el número de secuestrados. Por ello cobra mayor peso 
el profundo desfase de las cifras reales de este delito, mucho más cuando sus víctimas son miembros de la Fuerza Pública, porque generalmente se desconoce en qué condiciones se encuentran, excepto quienes ya han recuperado la libertad o sus restos han sido identificados. De hecho los datos oficiales de 2.800 casos de secuestro en general, verificados uno a uno por FDLP en coordinación con las Fuerzas Militares, la Policía Nacional, el DAS, la Fiscalía General y el CTI, después de evaluar distintas fuentes de información, permitieron establecer que 1.173 personas no están ya en cautiverio, pero sin datos complementarios (Henao, 2013).

Lo anterior conduce necesariamente a percibir el contexto del secuestro como el escenario de un proceso histórico ligado íntimamente a los significados que con el paso de los años ha adquirido, puesto que, considerando las relaciones significantes mediante las cuales son construidas las tramas de sentido, se tiende a legitimar muchas acciones delincuenciales como parte de un continuum de insensibilización frente al secuestro en la sociedad colombiana.

\section{EL DISCURSO DE LOS ACTORES SOBRE LOS SIGNIFICADOS DADOS AL SECUESTRO DE LOS MIEMBROS DE LA FUERZA PÚBLICA EN EL CONFLICTO ARMADO INTERNO}

Según CNMH (2013) es un hecho probado que a partir de 1960 hasta la fecha los GAI

no han sido un actor homogéneo en el conflicto armado colombiano y por el contrario, emergieron como una pluralidad de organizaciones armadas que luchan contra el Estado y que reivindican paradigmas ideológicos diferentes, muchas veces colisionando entre sí mediante intensas disputas violentas y solo coyunturalmente, concurrido en la unidad (p. 34)

1. Creado mediante el artículo 146 de la Ley 1448 del 2011 (reglamentado por el Decreto 4803 de 2011).

2. Creado en el artículo 154 de la misma ley, como un mecanismo para garantizar la atención y la reparación efectiva de las víctimas, desde el $1^{\circ}$ de enero de 1985.
Según la versión oficial, presentada por el Centro de Memoria Histórica $(\mathrm{CMH})^{1}$ y el Registro Único de Víctimas (RUV) ${ }^{2}$ se reconocen 166.069 civiles víctimas fatales, debidamente documentadas como producto del conflicto armado interno colombiano. Sin embargo, quedan por fuera de esta cifra 11.228 víctimas del mismo conflicto registradas por el CMH entre 1958 y 1984, también entre 1958 y 2012 el CMH reporta 40.787 combatientes muertos, dando como resultado un aproximado de 220.000 muertos. Es decir, ocho de cada diez víctimas fatales han sido civiles, sin contar los daños psicosociales, físicos, económicos, políticos, ambientales y culturales, entre otros, para los demás afectados directos e indirectos y el país en general (CNMH. 2013. p. 34).

De allí la necesidad de identificar las intencionalidades de los componentes de significado socialmente construidos alrededor del secuestro de miembros de la Fuerza Pública, con el fin de realizar un acercamiento a las tensiones contenidas en:

a) los discursos del gobierno y sus diversas instancias de compromiso social y cumplimiento de su rol de garante del respeto de los DDHH, del DIH y de la seguridad nacional,

b) e indudablemente la función transversal de los medios de comunicación en todos estos procesos que permea todos los espacios públicos y privados reclamando su derecho a la información $\mathrm{y}$ al secreto de sus fuentes.

En el ámbito de los objetivos e intenciones, el manejo discursivo del significado del secuestro de militares y policías, es asumido como un conjunto de hechos con un gran poder de sensibilización (pathos) de la sociedad.

Respecto a los medios de comunicación en el ámbito político y con relación al manejo discursivo dado al significado del secuestro de miembros de la Fuerza Pública por parte de los GAI, se encuentra el registro de las implicaciones adquiridas por el término "secuestro" y cómo constituyen elementos clave para reseñar el surgimiento de nuevos actores que tornan más complejo el escenario en estudio, al respecto la siguiente gráfica presenta este tipo de aportes: 


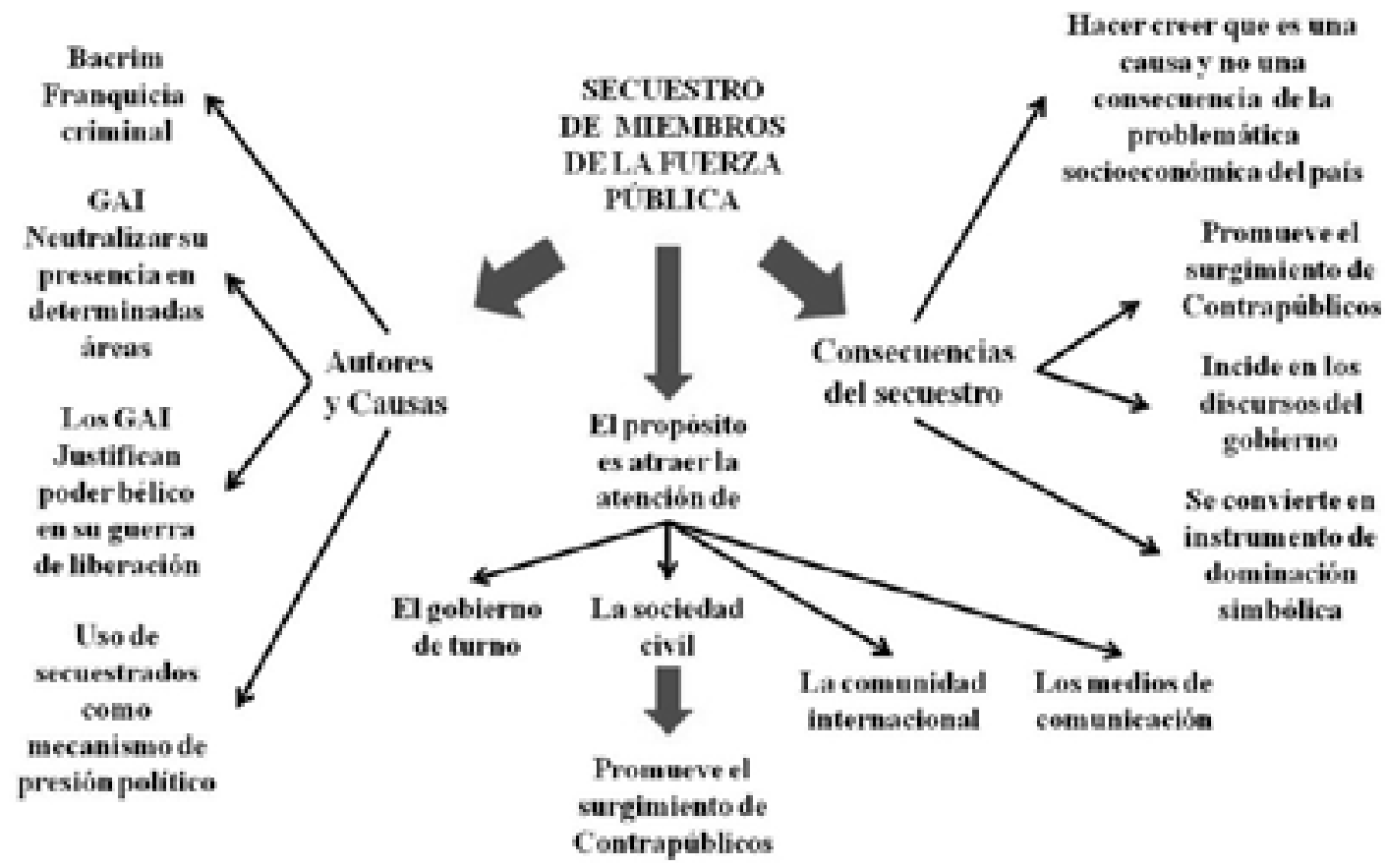

Figura 2. Registro de los medios del secuestro de miembros de la Fuerza Pública por GAI.

Fuente: Elaboración propia.

Antes de avanzar con la explicación de la figura 2, es preciso aclarar el concepto de contrapúblicos. Lo público ha venido cambiando epistemológicamente adaptándose a las exigencias de las democracias modernas, su afán es romper con la presión hegemónica porque el poder ya no es exclusividad de la élite, sino que ahora está permeado por las exigencias de los excluidos que reclaman ser reivindicados y reparados por la injusticia social que han padecido toda su vida.

Dicho lo anterior, se observa cómo los miembros de la Fuerza Pública constituyen un activo de alto valor estratégico, no son personas, sino cosificaciones susceptibles de ser negociadas hasta por franquicias criminales. El propósito de apoderarse de un militar o un policía es que a través de los medios la "chiva" llegue al mayor público posible y sobre todo que promueva el surgimiento de contrapúblicos que celebran una derrota más de la burguesía propinada por una insurgencia que les vende un mensaje esperanzador.

Simbólicamente aparece un escenario lleno de contradicciones, el secuestro de militares y policías deja de ser percibido como una problemática grave e inmediata, sin embargo, el de civiles adquiere una connotación distinta, más cercana, por eso se apoyan las marchas y protestas contra el secuestro y la violencia terrorista, a las cuales se unen los familiares de víctimas fatales y sobrevivientes de las Fuerzas Militares, marchas producto de los discursos surgidos de la misma sociedad civil, a veces con abierto, y otras con velado, apoyo del gobierno.

Lo interesante de la participación de los medios es que pueden apoyar o negar que el secuestro en general sea una causa y no una consecuencia de la realidad social y económica que vive el país. De igual modo, de manera indirecta, ingenua, premeditada o simplemente fuera de su control, contribuyen a promover el surgimiento de contrapúblicos, lo cual afecta negativa o positivamente las repercusiones que el gobierno e incluso los GAI quieran inducir en el pathos de quienes escuchan sus discursos. Por lo tanto, los medios ayudan a que el significado del secuestro de policías y soldados tienda a la cosificación mediática. 


\section{CONCLUSIONES}

En primer lugar es necesario plantear la necesidad de reconocer el disenso, antes que la negación estratégica, al exponer permanentemente un grupo de hombres y mujeres al servicio de la Fuerza Pública a las vicisitudes de un conflicto armado interno, convirtiéndolos en víctimas potenciales junto con sus familias, del flagelo del secuestro, actividad criminal que han salido no solo a combatir sino también a exponerse a ella.

Disentir de ambos extremos, signados por la violencia terrorista y a veces por los excesos de quienes portan las armas de la república, hace visible los modos en que se estaría encuadrando la búsqueda de la terminación del conflicto armado interno, puesto que de esa manera es como los distintos actores manejan discursivamente el fenómeno del secuestro en general y de miembros de la Fuerza Pública en particular, sobre todo por el espacio que continuamente ganan los contrapúblicos al percatarse que la retención ilegal de una sola persona, anulada como sujeto social al ser cosificada, por GAI o por franquicias criminales con las Bacrim y la Delcom, no es una de las causas de sus problemas socioeconómicos, todo lo contrario, es la consecuencia de la injusticia social en que ha vivido el país por generaciones.

Es así como el significado del secuestro de miembros de la Fuerza Pública pasa a convertirse prácticamente en una demostración del poder de anulación del Otro,

Es llamativo el hecho que crear verdaderos campos de concentración por parte de GAI como las FARC, ampliamente publicitados como muestra de su poder militar, donde decenas de militares, policías y hasta civiles eran exhibidos con cadenas al cuello, para citar solo un ejemplo de los niveles de barbarie alcanzados, se haya ido diluyendo y que ahora, en aras de generar una visión alternativa para un proceso de paz sea visto como algo anecdótico. Esto demuestra hasta qué punto llega la influencia de los medios de comunicación en la construcción del manejo discursivo del significado dado al secuestro de los defensores del Estado Social de Derecho.

Este tratamiento de un tema tan controversial como el secuestro de policías y militares, suele incluir, por una parte, las voces de quienes se opusieron vehemente y al final no consiguieron que ellos y sus familiares fueran reconocidos como víctimas del conflicto interno armado, y por la otra, a los que reclaman la plena aplicación del DIH, mediante el cual se igualarían los integrantes de los GAI con los miembros de la Fuerza Pública; postura que el gobierno, ante el creciente involucramiento de la población civil y la degradación del conflicto armado interno, ha derivado hacia una perspectiva de DIH focalizada, primero, en las exigencias del artículo 3 común a los Convenios de Ginebra de 1949, el cual debe ser observado por todas las partes involucradas y que como parte del jus cogens, hace parte del bloque de constitucionalidad definido por la Corte Constitucional y, segundo, en el Protocolo II adicional de 1977. Con este discurso, se afianzó el significado de víctimas.

Finalmente, en el conflicto armado interno que aún afecta a Colombia, es usual encontrar de forma generalmente velada la cosificación y la satanización del Otro, junto con la apelación a la defensa de la sociedad oprimida, todo inmerso en el populismo y el idealismo, eso conduce a que tanto los GAI (en estos momentos las FARC y el ELN) como el gobierno, apelen al pathos de la sociedad civil para justificar moralmente sus acciones, de donde la Fuerza Pública será vista como garante o enemiga, según el significado que quiera atribuírsele desde el ethos de los discursantes. 


\section{BIBLIOGRAFÍA}

- Cifras y conceptos. (2010). Una verdad secuestrada, 40 años de estadísticas del secuestro. 1970-2010. Disponible en el sitio. http://www.criteriosderuta.com/ Balance.pdf

- Centro Nacional de Memoria Histórica. (2013). Una guerra prolongada y degradada. Bogotá. Colombia. Disponible en el sitio web: http://centrodememoriahistorica. gov.co/descargas/informes2013/bastaYa/ capitulos/basta-ya-cap1_30-109.pdf

- Congreso de la República. Ley 1448 de junio de 2011. Por la cual se dictan medidas de atención, asistencia y reparación integral a las víctimas del conflicto armado interno y se dictan otras disposiciones. Reglamentada por el Decreto Nacional 4800 de 2011, Reglamentada por el Decreto Nacional 3011 de 2013. Diario oficial 48096.

- Congreso de la República. Ley 1592 de 2012. Por medio de la cual se introducen modificaciones a la Ley 975 de 2005. Diario oficial No. 48333 de diciembre 3 de 2012. Reglamentada por el Decreto Nacional 3011 de 2013.

- Corte Constitucional de Colombia.Sentencia 456 de 1997. MP. Jorge Arango Mejía \& Eduardo Cifuentes Muñoz)

- -------- Sentencia C-291 de 2007. MP. Manuel Cepeda Espinosa.

- Crossley, Nick. (1995). "Merleau-Ponty, El cuerpo evasivo y sociología carnal. En: Body \& Society, 1: 1. Disponible en el sitio web. http://www.scielo.org. bo/ scielo.php?script=sci_arttext\&pid =S1815-02762004000200012

- Defensoría del Pueblo del Valle del Cauca. (Feb. 10 de 2014). Informe de la existencia de franquicias criminales para la venta de secuestrados. Revista Semana. Disponible en: http://www.semana.com/ nacion/articulo/en-cali-se-incremento-ladelincuencia/376796-3

- Diario El Tiempo. (2014). Archivo de secuestros de aeronaves. Disponible en: http://www.eltiempo.com/archivo/ documento/

- Diccionario jurídico. Disponible en: http:// diccionario.leyderecho.org/

- Henao, Harlan. (2013). Realidad de las víctimas de secuestro en Colombia. Análisis, casos y cifras. Fondo Nacional para la Defensa de la Libertad Personal: Fondelibertad (FDLP). Ministerio de Defensa. Bogotá. Disponible en: www. fondelibertad.gov.co

- Iglesias, G. (2007). La propaganda en las guerras del siglo XX. 2a edición. Madrid: Editorial Arco Libros.

- Jiménez, Timoleón. Alias Timochenco. (Septiembre 5 de 2012). Declaración del Comandante en jefe de las FARC-EP, en La Habana. Disponible en: http://farccom. blogspot. com.co/2012/09/transcripcioncompleta-de-la.html

- Krauthasen, Ciro \& Sarmiento, Luis Fernando. (1991). Cocaína \& Co. Bogotá. Editorial Tercer Mundo.

- Laclau, E. y Mouffe, Ch. (2004). El discurso en la Hegemonía y estrategia socialista. México: FCE.

- Lauterpacht, H. (1947). El reconocimiento en el derecho internacional. Cap. XII. Los principios del reconocimiento de la beligerancia. Universidad de Cambridge. Inglaterra. Impresor Universidad de Cambridge.

- Mejía Azuero, Jean Carlo. (2013a). El militar, el policía y sus familias como víctimas de conflicto armado. Escuela Superior de Guerra. Revista de las Fuerzas Armadas. Volumen LXXXVI. No. 227. Bogotá.

- Mejía Azuero, Jean Carlo \& Marín Ramírez, Adriana Lucía. . (2015b). Miembros de las Fuerzas Armadas como víctimas, enfoque desde la justicia transicional en Colombia. Bogotá. Grupo Editorial Ibáñez. 200 pp. ISBN. 978-958-749-432-7 
- Mejía Azuero, Jean Carlo \& Chaib de Mares, Kelly. (2012c). Compendio Derecho Internacional Humanitario. Universidad los Libertadores, Equion Energy. Bogotá, Colombia. Primera edición

- Ortiz, Carlos Miguel (1985). Estado y Subversión en Colombia. La violencia en el Quindío años 50. Bogotá: CEREC - CIDER Uniandes

- Palacios Romeo, Francisco. (2008). Globalización discurso belicista y estado de excepción universal sobre la necesaria institucionalización del derecho a la Paz. Universidad de Zaragoza. ISSN 19887221. Disponible en el sitio web: http:// revistaseug.ugr.es/ index.php/revpaz/ article/view/417/462

- Real Academia de la Lengua - RAE, (2012). Diccionario de la lengua española. Madrid. Editorial de la RAE.

- Reyes, Raúl. (2005). Respuestas al cuestionario vía internet de la revista virtual La Haine. Disponible en el sitio web. http://www.lahaine.org/internacional/ objetivo_clase.htm

- Valencia Tovar, Álvaro. (1999). El Origen de las FARC. Citado en Revista Semana, Mayo 31 a Junio 7 de 1999, Edición No. 891. Bogotá.

- Van Dijk, Teum. A. (2004a). El discurso en el debate parlamentario. Revista de Lenguaje y Política. No. 2. pp. 93-129. Número especial sobre política de la identidad. Madrid. Editor: Paul Chilton.

- Van Dijk,TeumA.(2006c).Análisis deldiscurso, Discurso, poder y cognición social, Cátedra Unesco. Edición original de 1994. Disponible en el sitio web: http://www.geocities.com/ estudiscurso/vandijk_dpcs.html

- Vega G., Genaro. (2005). Seguridad nacional: concepto, organización y método. $2^{a}$ edición. México. Biblioteca Daniel Cosio Villegas.

- Villamizar, Darío (1995). Jaime Bateman: profeta de la paz. Bogotá: Compaz Von Hentig, Hans (1961). Estudios de psicología criminal. IV: El chantaje. Madrid: editorial Espasa-Calpe. 